\title{
O político e o jurídico na constituição das subjetividades sociais
}

Recebido 31, jan. 2005/Aprovado 20, mar. 2005

Freda Indursky

\section{Resumo}

Para trabalhar com a constituição de diferentes subjetividades sociais, serão examinadas duas subjetividades em conflito, inscritas em duas Formações Discursivas igualmente em confronto. Tal estudo será feito a partir do discurso do/sobre o $M S T$, tal como a midia o representa. A partir destas análises, veremos como se constroem interpretações conflitantes do jurídico.

Palavras-chave: politica; o politico; discurso jurídico; o jurídico. 


\section{Apresentando a questão}

O surgimento do movimento dos trabalhadores rurais sem terra no Brasil desencadeou uma discussão sobre os lugares políticos já consolidados e dotados de legalidade no espaço público. Lugares como propriedade rural e latifúndio encontram abrigo no discurso político e jurídico sobre o direito de propriedade da ter$\mathrm{ra}$, os quais remetem, por sua vez, a sujeitos legitimamente inscritos no espaço público tais como proprietários rurais, latifundiários, fazendeiros.

Esse fato se dá em contraposição a um não-lugar e remete àqueles que não encontram para si um espaço entre os lugares políticos já existentes, inscrevendo-se, pois, em sua origem, entre os excluídos da ordem social, política e jurídica brasileiras bem como do discurso político e jurídico sobre a propriedade rural.

Esse movimento, pois, ao auto-designar-se de movimento dos trabalhadores sem terra, desencadeou um processo de designação-sem-terra - que constrói, discursivamente, um novo sujeito político no espaço público brasileiro, o qual passa a falar em nome de um determinado segmento dos excluídos do cenário político brasileiro (INDURSKY, 2000, p. 17). Vale dizer: ao lado dos proprietários rurais, dos latifundiários e dos fazendeiros encontram-se agora os sem-terra, que representam o surgimento de um novo sujeito político, tal como o concebe Jacques Rancière: "[...] são os 'sujeitos do dissenso', aqueles que tomam a palavra quando e onde não deviam fazê-lo e apenas são sujeitos políticos quando o fazem" (FREIRE, 1995, p. 4-5). E este novo sujeito político surge no âmbito de um acontecimento discursivo, marcado pelo surgimento e consolidação do MST.

O encontro destes dois sujeitos antagônicos, aquele que, desde sempre, teve direito de falar sobre a questão da terra e a dela considerar-se proprietário, portanto um sujeito de direito, e o que surge do não-lugar, de dentre os excluídos, o sem-terra, e passa a falar de seu "direito à terra", se dá em um espaço litigioso em que o discurso jurídico passa a ser questionado pelo viés de uma interpretação ética de cunho conservador, pelo primeiro, e de natureza social, pelo segundo. Ou seja, tais sujeitos só podem instituir-se em Formações Discursivas antagônicas, o que explica a "interlocução" que se instaura entre estes dois sujeitos históricos, marcada, sempre, pelo dissenso, pelo desentendimento, pelo estranhamento, pela tensão, pela repúdia, pelo não reconhecimento dos direitos mútuos e das interpretações em conflito que regem as duas partes em litígio. Para tentar entender um pouco mais este dissenso, cito novamente Rancière. Este autor, para explicar o que seja politica, afirma que

política é antes de mais nada o conflito sobre a existência de uma cena comum, sobre a existência e a qualidade daqueles que nela se fazem presentes. É necessário inicialmente estabelecer que 
a cena existe para o uso de um interlocutor que não a vê e que não tem razão alguma para vê-la, pois ela não existe (RANCIÈRE, 1995, p. 49, grifo do autor).

A partir da reflexão de Rancière, percebe-se que o grande problema que se estabelece no cenário político brasileiro, no que concerne ao litígio que envolve proprietários rurais, de um lado, e os sem-terra, de outro, consiste no fato de que os primeiros não reconhecem a existência dos segundos como seus interlocutores, isto é, como sujeitos de direito e não o fazem por não entendê-los qualificados para o diálogo. E, se não os reconhecem, a cena discursiva de interlocução não se constitui. $O$ referido litígio constrói uma zona de "interincompreensão constitutiva" (MAINGUENEAU, 1989, p. 119-120) e, por conseguinte, mútua, que se constrói sobre o desentendimento e que explica o conflito de interpretação instaurado entre ambas as partes, entre os dois sujeitos históricos em conflito.

Em função da ausência de uma legítima interlocução, os sem-terra traçaram uma estratégia política que visa conquistar seu acesso à terra. Para tanto, mobilizam uma prática política que desencadeia, por sua vez, uma prática discursiva que põe constantemente a reforma agrária na ordem do dia do discurso social brasileiro, questionando a eficácia da ação governamental e sua vontade política de efetivamente redistribuir as terras no Brasil, polemizando o discurso jurídico brasileiro sobre a questão da propriedade. Podemos chamar estas práticas do MST de atividade política, que, segundo Rancière, "desloca um corpo do lugar que the havia sido atribuído ou troca a destinação de um lugar; ele faz ver o que não tinha espaço para ser visto, faz ouvir um discurso onde apenas havia ruído anteriormente" (RANCIÈRE, 1995 , p. 53, grifo do autor).

Certamente as práticas discursivas e não-discursivas do MST podem ser entendidas como atividades politicas, pois dão ao movimento visibilidade e os discursos que provocam possibilitam a lisibilidade de seus reclamos. À luz da reflexão de $\mathrm{H}$. Arendt, podemos entender melhor a atividade política do MST. Segundo a autora, uma das atividades fundamentais que caracterizam a condição humana é a ação. Segundo ela, a ação é a única atividade que se exerce diretamente entre os homens, sem a mediação das coisas ou da matéria. E esta atividade aponta para a pluralidade, ou seja, ela não é realizada por um indivíduo isolado. Por esta razão, a "ação é a condição distintiva da condição humana - é a atividade política por excelência" (ARENDT, 2003, p. 15-17). Ou seja: para a autora, as atividades nãodiscursivas são da ordem da política. E necessitam fortemente do discurso para se fazerem entender, pois, como afirma ainda a autora "nenhuma atividade humana precisa tanto do discurso quanto a ação" (ARENDT, 2003, p. 188). 
Para Arendt, a pluralidade humana se caracteriza por um duplo traço: a igualdade e a diferença. Diz ela: "se não fossem iguais, os homens seriam incapazes de compreenderem-se entre si [...]. Se não fossem diferentes [...] não precisariam do discurso ou da ação para se fazerem entender" (ARENDT, 2003, p. 188). Ou seja: é, no caso em análise, pelo fato de serem diferentes que os homens necessitam da atividade política, seja ela a ação, seja ela o discurso, pois, sem o discurso, a ação deixaria de ser ação. E a autora vai ainda mais além, ao afirmar que "é através do discurso sobre as questões do mundo em comum que a ação assume caráter político específico, que se manifesta na cena pública, que nunca é consensual. É, pois, na ação e no discurso que os homens mostram quem são" (ARENDT, 2003, p. 188-193).

A reflexão de Arendt nos ajuda a perceber que as atividades políticas do MST apontam para dois aspectos essenciais: elas fazem parte de uma pluralidade e, no interior desta pluralidade, há diferenças muito fortes sobre o que se entende por uma política da/para a terra. Tais diferenças deixam claro que este é um campo onde há dissenso. E tanto as ações como os discursos que acompanham estas ações apontam para isto. Para que suas demandas se tornem públicas, o sujeito do MST usa a ação para dar-lhes visibilidade e, através desta visibilidade, fazèr circular seu discurso. Ou seja: em função da ausência de uma cena pública de interlocução, este sujeito necessita da mídia para se fazer ouvir pela sociedade e pelo governo.

Dito diferentemente: os discursos midiáticos, ao funcionarem como uma cena pública, são atravessados por todos os traços que caracterizam a ação humana e a política. Ou seja: a mídia constrói espaços onde podem se manifestar a pluralidade, a diferença e o dissenso. Vale dizer: a mídia pode funcionar como um simulacro da cena pública onde se manifestam diferentes subjetividades, onde se inscrevem interpretações antagônicas. Entretanto, é necessário imediatamente salientar que a mídia não é uma cena pública, mas pode funcionar como tal, como se fosse seu simulacro, pois os diferentes sujeitos sociais aí se manifestam, quando isto se torna possível, através de um mediador, seja ele o repórter, o redator, o editor. Em função disso, não é possível esperar fidelidade quanto aos sentidos que o discurso jornalístico veicula, mas este novo sujeito político, o sem-terra, pelo viés do discurso midiático, adquire a capacidade de produzir cenas polêmicas, demandas e discursos em confronto que permitem visualizar a condição humana dos trabalhadores sem-terra em confronto com os proprietários rurais. Isto é: através do discurso da mídia é possível dar visibilidade à contradição que se instaura entre estes dois sujeitos em conflito e suas lógicas em colisão. 
O discurso da mídia abriga, pois, um conjunto de discursos em tensão, dentre os quais destaco sobremodo o discurso destas duas subjetividades em conflito: os proprietários rurais e os sem-terra. Esses discursos são provenientes de lugares políticos diferentes, produzindo um espaço discursivo marcado pelo antagonismo de Formações Discursivas em confronto. E, na ausência de uma cena discursiva de interlocução, esses discursos podem ser apreendidos pelo viés das narrativas da imprensa. São elas que dão maior ou menor visilidade ao movimento, maior ou menor fidelidade a suas demandas, mais ou menos clareza suas aos seus argumentos.

É no âmbito dessa confluência de discursos em tensão que o presente artigo encontra seu propósito, pois vou analisar, pelo viés do processo de designação que a tomada da terra aí desencadeia, o político e o jurídico que perpassam essa rede de formulações discursivas e suas implicações éticas.

\section{A política e o político}

Antes de passar às análises propriamente ditas, desejo refletir um pouco sobre as três noções que estão mobilizadas e entrelaçadas nesse trabalho: a política, o político e o jurídico.

Inicialmente, é preciso distinguir a política do político. Há uma tendência em confundir estas duas noções, o que não ajuda a refletir teoricamente. Diria, acompanhando Rancière (1995, p. 22), que "a política não se ocupa dos vínculos entre os indivíduos, nem das relações entre os indivíduos e a comunidade; a política é da alçada de uma contagem das 'partes da comunidade', contagem esta que é sempre uma falsa contagem".

É preciso parar um pouco sobre esta afirmação de Rancière para entender melhor a que se refere quando fala em uma falsa contagem. Essa falsa contagem aponta para um fato muito importante: quando, em política, a comunidade é referida, tem-se a ilusão de que toda a comunidade está sendo considerada. Mas não é assim que, de fato, as coisas se passam. Há sempre, em uma comunidade, uma parcela dos que não são contados. Trata-se dos excluídos, dos sem-parcela. No caso que aqui nos mobiliza, os sem-parcela podem ser entendidos como os sememprego, os sem-teto, os sem-terra. Estes são os que não são contados. Por conseguinte, para o autor, a comunidade política é dividida. Dito diferentemente: a política é a esfera da atividade de um comum que só pode ser litigioso. De sorte que, quando entendemos política, de um modo geral, como um conjunto de "processos através dos quais se operam a agregação e o consentimento das coletividades, a organização dos poderes, a distribuição dos lugares e funções e os sistemas de legitimação desta distribuição" (RANCIĖRE, 1995, p. 51), estamos esquecendo/encobrindo que, de fato, a política se faz no dissenso, para 
lembrar Arendt, ou no desentendimento, para retomar Rancière. Por esta razão, Rancière entende que política é o conflito em torno da existência de uma cena comum, em torno da existência e da qualidade daqueles que estão ali reunidos. Por isto, afirma o autor,

existe política porque aqueles que não têm direito de serem contados como seres falantes, conseguem ser contados e constituem uma comunidade pelo fato de se colocarem em comum o dano que nada mais é que o próprio enfrentamento, a contradição de dois mundos alojados num só: o mundo em que estão e o mundo em que não estão...o conflito separa os dois modos de estar-junto humano, dois tipos de divisão do sensível, opostos em seu princípio e, no entanto, entrelaçados um no outro nas contagens impossíveis da proporção, assim como nas violências do conflito (RANCIÈRE, 1995, p. 40).

Como podemos observar, a descrição de Rancière permite caracterizar a política existente hoje, no Brasil, em torno da questão agrária: grupos de sem-parcela, de sem-terra, que não são contados como trabalhadores rurais, entram em conflito com uma outra parcela, os proprietários rurais, que são contados e que não reconhecem os sem-terra como tendo o direito de serem contados. E os sem-terra, por não serem reconhecidos, não conseguem estabelecer uma cena pública comum. E, por não terem acesso a esta cena pública, provocam dois fatos: usam a ação e esta, por sua vez, produz notícia. Desta forma, fica constituída uma cena pública, a única que lhes é facultada, e o fato de conseguirem, com sua prática, abrir espaço na mídia produz um fato político. Eis aí um primeiro modo de distinguir a política do político. O político é o resultado da ação política. Mas, para melhor distinguir estas duas categorias, passamos a examinar o modo como pensa Corten.

Segundo Corten, o político "é, de fato, em si mesmo, uma representação" (CORTEN, 1999, p. 37). E o autor continua afirmando que por "representação do político" entende a "cena onde os elementos que perpassam a sociedade são vistos como 'forças' e vistos como forças políticas" (CORTEN, 1999, p. 37). A isto desejo acrescentar: a cena discursiva é lugar de tensão. É espaço de confronto. E, como vimos anteriormente, no caso do discurso do/sobre os sem-terra, a cena discursiva possível consiste em um lugar-fronteira, onde se defrontam os sujeitos históricos desse litígio.

Em meu entender, o político se constrói através dos discursos em circulação no discurso social. Ou seja, entendo o político como o resultado da trama de diferentes processos discursivos, atravessados pelo interdiscurso e recortados por diferentes formações discursivas.. É preciso salientar que, para a análise do discurso, o que conta não é a política, mas o político. Ainda citando Corten, fazemos uma nova distinção que se im- 
põe para nosso trabalho: "o político [...] não corresponde ao discurso político [...] De um lado, o político não se limita ao campo do discurso político mas, de outro, não se estende a toda tela discursiva como multiplicidade imanente de relações de poder". (CORTEN, 1999, p. 38, grifos do autor).

Ou seja, não se trata de afastar/negar o discurso político, mas o que nos mobiliza, nos discursos políticos, é o político que, através deles, podemos captar e analisar. E mais: no âmbito do presente trabalho, procuramos o político pelo viés do discurso político veiculado pela mídia. Vale dizer: o político tampouco se confunde com o jornalismo político. O político é, pois, trabalho de construção discursiva do social.

\section{O político e o jurídico}

Interessa também, no âmbito desse trabalho, aprofundar o modo como percebo o jurídico. Também aqui não ocorre superposição entre o discurso jurídico e o jurídico. Na minha concepção, o discurso jurídico é construído pelo conjunto de textos jurídicos que estabelecem a legislação de um país, através da qual a sociedade é ordenada. Ou seja, o discurso jurídico é assunto de especialistas: juristas, juízes, legisladores, etc. Enquanto que o jutrídico é resultado do trabalho de construção discursiva, instaurado na cena discursiva, pelos diferentes sujeitos históricos que nela se confrontam, pelo viés dos discursos em circulação no discurso social.

Ou seja, não se trata de afastar/negar o discurso jurídico, mas de captar os diferentes gestos de interpretação que, a partir dele, se produzem. Estes gestos de interpretação do texto legal, instaurados por sujeitos não-especialistas, tecem processos discursivos que vêem afetados pelo interdiscurso e que também podem ser recortados por diferentes formações discursivas. É sobre estes processos discursivos, apreendidos no discurso da imprensa, que vamos nos inclinar para examinar o jurídico que se inscreve nos discursos da/sobre a questão da terra.

É evidente que o político e o jurídico não existem separadamente, ao contrário do discurso político e do discurso jurídico. Político e jurídico convivem de forma imbricada nos discursos em circulação, de um modo geral e, por conseguinte, no discurso da mídia, de modo particular, que é o que interessa no artigo em tela. Não só estes discursos se superpõem como há algo que promove esse entrelaçamento. Refiro-me à ética. É a ética que estabelece o amálgama do político com o jurídico. Vejamos, pois, como entender a ética no âmbito do presente trabalho.

Segundo Vásquez (1999, p. 23), "a ética é a ciência do comportamento moral dos homens em sociedade". Já, segundo este mesmo autor, "a moral é um conjunto de normas, aceitas livre e conscientemente, que regulam o comportamento individual e social dos homens" (1999, p. 63). Ou seja, a moral possui uma 
qualidade social. E o autor, mais adiante, acrescenta que "a função social da moral consiste na regulamentação das relações. entre os homens [...] para contribuir no sentido de manter e garantir uma determinada ordem social" (1999, p. 69).

Decorre de tudo quanto precede, embora política e moral não se confundam, que ambas refletem sobre a ordem social e sobre a vida do homem em sociedade.

Segundo Vásquez (1999, p. 97) "de todas as formas de comportamento humano, o jurídico é o que mais intimamente se relaciona com a moral, porque os dois estão sujeitos a normas que regulam as relações dos homens". Ainda segundo o autor, "a moral e o direito mudam quando muda historicamente o conteúdo de sua função social" (1999, p. 97).

Ou seja: a moral e o direito mudam através dos tempos. Difícil conceber o direito e a moral como formas imutáveis. Sabese que as condições econômicas, sociais e políticas em que a existência do homem ocorre não se perpetuam. E, se assim é, mudanças são esperadas no modo de interpretar a ordem social e as leis que a ordenam. Diria mesmo que é com base nessas possíveis mudanças que se pode falar em uma ética conservadora e em uma ética social, tal como faço ao longo deste artigo, pois tampouco é possível conceber uma ética universal. Na verdade, não há uma só ética. Há éticas que são definidas a partir de diferentes lugares sociais, de diferentes subjetividades históricas. Dito de outro modo: éticas diversificadas e concomitantes. Entendo por ética conservadora uma ética que percebe a lei como imutável, perpetuando para sempre os direitos conquistados pelos indivíduos, sem levar em conta as necessidades das demais classes sociais. Por outro lado, falo de uma ética social, para referir o questionamento feito à moral que sustenta a imutabilidade da lei e dos direitos adquiridos. Em suma, estamos frente a uma ética social quando se passa a falar de direitos sociais em detrimento dos direitos individuais.

\section{Encaminhando as análises}

Cabe ainda esclarecer que vou examinar tais questões basicamente à luz da noção de Formação Discursiva (também poderá ser representada por FD), tal como foi formulada por Pêcheux - aquilo que pode e deve ser dito - e a ela vou associar a noção de ética. Nesse sentido, entendo que uma FD pode ser concebida como um dominio de saber que regula aquilo que pode e deve ser dito por um sujeito histórico nela inscrito, contemplando tanto a dimensão politica quanto a dimensão jurídica do discurso, entrelaçadas por uma visada ética. Ou seja, estou aqui formulando uma concepção de FD, alicerçada neste lugar-fronteira (INDURSKY, 2002) onde ocorre este cruzamento de discursos e que se constitui em um espaço de deslizamentos de sentido, um espaço de releituras. 
Neste trabalho, vou examinar duas diferentes designações que remetem à luta pela terra no Brasil: ocupação e invasão, ${ }^{1}$ examinando-as no cruzamento do político com o jurídico para verificar como tais designações manifestam subjetividades em confronto, as quais dão origem a um conflito de interpretação do jurídico. Para examiná-las, vou construir dois diferentes recortes discursivos com seqüências discursivas recortadas de matérias jornalísticas dos anos 1995-1996, publicadas na Folha de São Paulo (doravante, também pode ser FSP), jornal de grande penetração nacional.

\section{A designação ocupação}

Os trabalhadores sem-terra, cansados de aguardar pela realização da reforma agrária, decidiram acelerar o processo de redistribuição das terras. Para tanto, localizam terras consideradas improdutivas para nelas instalarem seus acampamentos e darem início ao seu cultivo e, dessa forma, pressionar o governo a agir, desapropriando as terras ocupadas para tornálas disponíveis para posterior assentamento. Seu propósito, expresso pelo lema "ocupar, resistir, produzir", é o de acelerar o processo de Reforma Agrária, colocando o Governo face a situações, se não de direito, pelo menos, de fato. E, assim procedendo, designam sua prática de ocupação, como veremos através do recorte que segue.

1 - "Vamos intensificar as ocupações. É assim que vamos ajudar o governo a assentar as 40 mil famílias até o fim do ano", afirmou Rainha (ALONSO, 1995).

2-A política de "ocupações", segundo José Rainha Jr., líder do MST no Pontal do Paranapanema, não é planejada perante o dilema "terras públicas versus terras privadas". O que orienta essa política, segundo ele, é outra discussão: áreas improdutivas devem ser ocupadas enquanto houver pelo menos uma familia sem ter onde plantar (SÁ, 1995).

O recorte acima é representativo do processo de designação da tomada da terra por parte dos sem-terra. Na FD em que os sem-terra se inscrevem, as terras são ocupadas, é lícito mesmo fazerem-se ocupações, pois "as terras são improdutivas" ou devolutas e há famílias que querem, mas não têm "onde plantar". Ou seja, trata-se de uma política dos sem-terra para acelerar as ações governamentais, amparada em uma ética social e revisionista do discurso jurídico sobre a propriedade privada e sobre o direito à terra.

Assim procedendo, promovem uma discussão que mobi-

Estas duas designaçōes já foram objeto de trabalho anferior (INDURSKY, 1999), onde examinei os efeitos de sentido que tais designaçōes projetam no discurso da imprensa sobre o MST. liza fortemente o jurídico e está amparada numa questão de ordem ética: tem direito à terra não aquele que legalmente a possui, mas aquele que a faz produzir ou que é capaz de fazê-la produzir. Ou seja, se a terra está improdutiva é o fazendeiro 
que a ocupa irregularmente. Este sentido só pode ser produzido quando alicerçado em uma releitura do jurídico à luz de uma ética conservadora. Como se vê, há uma inversão na interpretação do que é legítimo, que acaba por instaurar outro ponto de tensão que pode ser representado por dois pares de termos jurídicos: legalidade $x$ legitimidade e propriedade $x$ posse. Nesse litígio, em que os sentidos do discurso jurídico são questionados pelo viés de uma ética socialista, o legítimo se sobrepõe ao legal e a posse à propriedade. Essas novas formulações promovem deslocamentos nos sentidos já estabelecidos sobre a questão da propriedade agrária no Brasil e vão construindo o que designei mais acima de jurídico.

[...] Os sem-terra, na sua prática, não têm como deixar de questionar a legalidade da propriedade, não podem deixar de considerar ilegítimo [...] o que é legal, que é a possibilidade de alguém possuir mais terra do que pode trabalhar $[\ldots]$, nem deixar que outros utilizem, mesmo sob pagamento de renda. Se não fosse assim, não se sentiriam encorajados a ocupar a terra (MARTINS, 1985, p. 103)

Como é possível perceber pela reflexão de Martins, está em discussão a ética que subjaz à propriedade rural, tal como ela é praticada no Brasil e, juntamente com ela, poder-se-ia mesmo dizer que está em questionamento a ética do ordenamento jurídico que permite propriedades rurais tão extensas no país, pois $1 \%$ dos proprietários rurais detêm $46 \%$ das terras brasileiras. Dito em outras palavras, as propriedades rurais, do ponto de vista jurídico, são consideradas legais, mas, do ponto de vista de uma ética social, ilegítimas, dando lugar à construção do jurídico e estimulando uma prática de ocupações. Ou seja, mobilizam-se aí praticas sociais - discursivas e não-discursivas.

Essa nova postura está em pleno confronto com a posição conservadora dos proprietários rurais, os quais se apóiam em um discurso jurídico que foi produzido a partir de um determinado lugar social que se identifica com esse pensamento. Dito de outra forma, o discurso jurídico sobre a propriedade rural foi concebido por juristas que pertencem, indubitavelmente, ao mesmo lugar social dos proprietários rurais. $\mathrm{Ou}$, ainda, por juristas que se identificam com a FD em que se inscrevem os proprietários de grandes latifúndios rurais. Ou seja, os legisladores legislam em causa própria ou em nome de seus pares, sem se preocupar com aqueles que vivem da terra, mas não a possuem, pois ela já tem um proprietário. É o que se pode perceber a partir do próximo recorte. 


\section{A designação invasão}

Neste recorte, vou analisar a segunda posição-sujeito envolvida nesse processo de designação. Trata-se de designar de invasão a ocupação das terras praticada pelos sem-terra, como é possível verificar no recorte que segue.

3-Os fazendeiros do Pontal do Paranapanema realizam hoje protesto contra as invasões de terra [...] "Não somos contra a reforma agrária. Somos contra a baderna que as invasões causam, trazendo prejuízos ao conjunto da sociedade", afirmou Célio Souza, vice-presidente do Sindicato Rural de Presidente Prudente (MALAVOLTA, 1995a).

4-O INCRA está incentivando o desrespeito à lei e à propriedade ao permitir que os sem-terra invadam fazendas e façam exigências ao governo. A afirmação foi feita à Agência Folha em Bauru, SP, pelo presidente do Sindicato Rural de Bauru e Diretor da Federação da Agricultura de SP, Maurício Lima Verde Guimarães (MALAVOLTA, 1995b).

Os fazendeiros, no discurso de seus representantes, apresentam sua própria designação para a prática dos sem-terra. Essa designação diversa aponta para uma posição-sujeito igualmente diversa daquela assumida pelos sem-terra, a qual se inscreve em uma formação discursiva que lhe é antagônica. Tal antagonismo gera uma outra interpretação que entra em confronto com a interpretação da posição-sujeito dos sem-terra. Face a este conflito de interpretações, pode-se perceber que estas duas subjetividades sociais se delimitam e se excluem mutuamente. Inscrevem-se em duas FD antagônicas que as conduzem a desenvolver resistência aos sentidos de uma em relação a outra: o que é legítimo para a primeira é ilegal para a segunda; o que é legal para a segunda é imoral para a primeira. Subjetividades em confronto, interpretações em conflito.

Esse litígio apóia-se no jurídico e em suas implicações, ou seja, os fazendeiros protestam contra a "baderna", contra "o desrespeito à lei e à propriedade", procurando fazer valer a letra da lei, pretendendo que o discurso jurídico mantenha inalterado o direito de propriedade da terra.

Nessa formação discursiva, ignorar que a terra possui um proprietário e nela acampar mobiliza o jurídico, que garante o direito de propriedade (art. $5^{\circ}$ da Constituição, item XXII), e, com base nele, os latifundiários chamam os sem-terra de "invasores" e aos seus líderes de "formadores de quadrilha". Assim procedendo, ao mesmo tempo em que desqualificam os sem-terra, enquanto seus interlocutores, os transformam em fora da lei. Dito de outra forma: sujeitos de direito não dialogam com indivíduos fora da lei. Brincando um pouco mais com estes dois efeitos de sentido, poderíamos falar em sujeitos dentro da lei e em indivíduos fora da lei. 
A designação invasores, com todos os efeitos de sentido que dela provêm, está garantida por um discurso que sacraliza e imobiliza a noção de direito de propriedade, instituindo a perpetuação desse valor que se apresenta como absoluto e imutável e que sustenta o direito de que se arrogam os fazendeiros para se armar com o objetivo de proteger sua propriedade, matando, se necessário for, seus invasores. E, quando chegam a matar, nunca transpõem o limite do dentro da lei, (vide o julgamento do massacre dos sem-terra, em Corumbiara), nunca transpõem tal limite, pois o fazem para proteger sua propriedade, o fazem em nome da propriedade privada, apoiados no direito de propriedade. Estão, pois, apoiados na lei e dela não se afastam, não correndo o risco de se tornarem fora da lei.

\section{Conflitos de interpretação e efeitos de sentido}

Como é possível verificar, no discurso dos sem-terra, a tomada da terra é designada de ocupação, enquanto no discurso dos proprietários rurais, a prática dos sem-terra é designada por invasão.

Essa dupla designação poderia, numa primeira visada, ser considerada pelo viés da sinonímia, pois tanto ocupação quanto invasão remetem referencialmente à prática adotada pelos semterra. Entretanto, tal não é o caso. Senão, vejamos.

Ocupação tem como referente a terra improdutiva. Invasão constrói como referente a terra privada. A primeira, por tratar da terra improdutiva, trabalha o sentido ético de uma terra que, por ser improdutiva, deve ser redistribuída para aqueles que, se assim o desejarem, possam cultivá-la para dela tirar a sua subsistência e a dos seus. A segunda, por possuir um proprietário, põe em relevo o sentido jurídico de violação da propriedade privada. A primeira remete à idéia de ação pacífica exercida sobre terras abandonadas e faz ressoar um já-dito anterior, proveniente do discurso religioso da ala progressista da Igreja Católica no Brasil. Vale dizer: a pastoral da terra, as comunidades eclesiais de base e a Teologia da Libertação. A segunda traz consigo o efeito de sentido de violação da propriedade privada, ou seja, discursiviza o desrespeito à lei e faz soar o discurso jurídico sobre o direito de propriedade e a ilegalidade daqueles que adotam a prática da invasão. Como é possível perceber, estas duas designações remetem para duas posiçõessujeito opostas, que se inscrevem em FD antagônicas, instaurando dois discursos que se delimitam e se excluem mutuamente, construindo aí um conflito de interpretações entre esses dizeres e saberes sobre a terra e sua posse.

Essa dupla nomeação mobiliza saberes diferentes que se apóiam em paradigmas éticos, políticos e jurídicos diversos, dando lugar à construção de fatos políticos distintos. Essa du- 
pla nomeação imbrica discursivamente o político, o jurídico e a ética de forma inextricável, daí resultando a delimitação de duas formações discursivas antagônicas, de duas subjetividades históricas tão distintas, de saberes tão diversos, de interpretações tão conflitantes.

E esse intrincamento põe em movimento uma discussão sobre os lugares políticos no Brasil bem como as diferentes subjetividades sociais que ocupam tais lugares políticos, no exercício de suas práticas discursivas. Vale dizer que as duas designações coexistem na língua, mas o uso de uma ou de outra mobiliza discursivamente diferentes interpretações que resultam em efeitos de sentido diferentes os quais remetem a processos discursivos igualmente diferentes, que se encontram em situação de co-ocorrência no espaço discursivo desenhado pela imprensa em seu discurso do/sobre o MST.

\title{
Para encerrar
}

É exatamente esse segundo direito - o direito à propriedade esquecido/silenciado pelos proprietários rurais e pelo discurso midiático, que dá sustentação a releituras legais que estão na base da produção de novos sentidos, com a conseqüiente instauração de um novo sujeito histórico que não mais se submete passivamente à ordem jurídica estabelecida, a qual, de fato, não contempla os excluídos do processo social. Esse novo sujeito pretende ver discutida a legalidade do direito de propriedade, propugnando pela legitimidade do direito à propriedade.

\begin{abstract}
In order to work on the constitution of different social subjectivities, I will examine two subjectivities in conflict, inscribed in two discursive formations, also in confrontation with each other. This study will be carried out from the discourse about/on the MST, as the media represents it. From the analysis, I will point out how conflictive interpretations of the juridical (legal system) are constructed.
\end{abstract}

Keywords: politics; the political; juridical discourse; the juridical. 


\section{Referências}

ALONSO, George. Sem-terra ameaçam com matança de bois. Folha de São Paulo, São Paulo, p. 1-11, 17 out. 1995.

ARENDT, H. A condição humana. Rio de Janeiro: Forense Universitária, 2003.

CORTEN, A. Discurso e representação do político. In: INDURSKY, F.; FERREIRA, M. C. L. (Org.). Os múltiplos territórios da análise do Discurso. Porto Alegre: Sagra-Luzzatto, 1999.

FREIRE, Vinícius Yorres. Os riscos da razão. Folha de São Paulo, São Paulo, Caderno mais! p. 5-10, 10 set. 1995.

INDURSKY, F. A função enunciativa do porta-voz no discurso sobre o MST. Revista ALEA: Estudos Neolatinos, Rio de Janeiro, v. 2, n. 2, set. 2000.

. De ocupação a invasão: efeitos de sentido no discurso do/sobre o MST. In: INDURSKY, F; FERREIRA, M. C. L. (Org.). Os múltiplos territórios da análise do discurso. Porto Alegre: SagraLuzzatto, 1999.

. O entrelaçamento entre o político, o jurídico e a ética no discurso do/sobre o MST: uma questão de lugar-fronteira. Revista da ANPOLL, São Paulo, n.12, p. 111-132, 2002.

MAINGUENEAU, D. Novas tendências em análise do discurso. Trad. Freda Indursky. Campinas, SP: Ed. da Unicamp: Pontes, 1989.

MALAVOLTA, Luiz. Fazendeiros protestam hoje contra invenções. Folha de São Paulo, São Paulo, p. 1-9, 27 nov. 1995a.

Para produtor, INCRA incentiva desrespeito à lei. Fotha de São Paulo, São Paulo, p. 1-9, 23 out. 1995b.

MARTINS, J.S. A militarização da questão agrária no Brasil. Petrópolis: Vozes, 1985.

PECCHEUX, M. Semântica e discurso. Campinas: Ed. da UNICAMP, 1988.

RANCIÈRE, J. La mésentente. Paris: Galilée, 1995.

SÁ, Xico de. São Paulo tem terra para assentar 67 mil famílias. Folha de São Paulo, São Paulo, p. 1-8, 20 out. 1995.

VÁSQUEZ, A.S. Ética. Rio de Janeiro: Civilização Brasileira, 1999. 